\title{
Approaches for Enhancing Microbial Degradation of Synthetic Plastics: A Review
}

\author{
Rashmi $^{1^{*}}$, Rakesh Kumar ${ }^{2}$ and D.V. Pathak ${ }^{2}$ \\ ${ }^{1}$ Deendayal Upadhyay Kaushal Kendra, Central University of Haryana, Mahendragarh, \\ Haryana, India \\ ${ }^{2}$ Department of Microbiology, Chaudhary Charan Singh Haryana Agricultural University, \\ Hisar, Haryana, India \\ *Corresponding author
}

\section{A B S T R A C T}

\begin{tabular}{|c|}
\hline Keywords \\
\hline $\begin{array}{l}\text { Microbial } \\
\text { Degradation, } \\
\text { Synthetic plastics, } \\
\text { Polymer }\end{array}$ \\
\hline Article Info \\
\hline $\begin{array}{l}\text { Accepted: } \\
\text { 15 December } 2019 \\
\text { Available Online: } \\
\text { 20 January } 2020\end{array}$ \\
\hline
\end{tabular}

The term plastic is given to various polymers which can be moulded in different shapes as per the requirement in different sectors. Some plastics are biodegradable while others are not. The biodegradability of plastics depends upon many factors such as polymer characteristics and growth conditions. Because of complex polymeric structure and high molecular weight microorganisms cannot degrade plastics efficiently. So, scientists discover new ways to improve biodegradation. In this review, factors that can enhance plastic degradation by microorganisms including pre-treatment and blending of plastics, use of potent strains, modification in growth medium and biofilm formation are discussed.

\section{Introduction}

Plastics are polymeric substances made up of various synthetic or semi-synthetic compounds (Saminathan et al., 2014). They are synthesized from petrochemicals which are obtained from natural gas, coal and oil. The most common plastics used in different industries and agriculture are polyethylene (PE), polycaprolactone (PCL), polypropylene (PP), polyvinyl chloride (PVC), polyurethane (PUR), polyhydroxyalkanoate (PHA), polyhydroxybutyrate (PHB), polybutylene succinate (PBS), polyethylene terephthalate (PET), polylactide (PLA), and polystyrene (PS) (Muhamad et al., 2015; Yoshida et al., 2016). Most of these plastics including PE, PP, PS, and PVC are non-biodegradable and get accumulated in the environment in large amount because of improper management of waste. It resulted in a big threat to all forms of life on the planet (Sharma and Dhingra, 2016). It not only caused serious health issues but also affected soil fertility severely. The rate of generation of plastic waste is about 57 million tons annually, as per estimation on global level (Vijaya and Reddy,2008). 
Moreover, deposition of plastic waste in oceans is much larger than land which is a serious threat to life of aquatic animals and fishes (Comăniță et al., 2016). So, it is a big concern to scientists to deal with the problem of increasing accumulation of nonbiodegradable plastic waste in the environment day by day (Tokiwa and Calabia, 2008). One way to overcome this problem is the use of biodegradable plastics in different sectors. But because of low stability their use in industries is limited (Rujnić-Sokele and Pilipović, 2017). Plastics are complex molecules made up of long chains of repeating units of carbon atoms. The monomers are connected to each other with strong carbon-carbon bonds. Because of their polymeric structure and hydrophobicity they are very resistant to degradation (Ghosh et al., 2013). They are deliberately made in that way so that they can persist without damage for long times. Because of this it is very difficult for microorganisms to attack them (Vijaya and Reddy, 2008). However, slow breakdown of plastics over long period of time is observed in nature. Also, many studies have been conducted which showed the partial degradation of non-biodegradable plastics by various microorganisms including bacteria and fungi. Microorganisms employ different methods for degradation of such plastics including use of plastic fragments as a source of carbon and energy or indirectly by using exoenzymes (Mohanty et al., 2000; Sharma et al., 2003; Ghosh et al., 2013). Many bacterial enzymes play important role in biodegradation (Tokiwa et al., 2009; Muhamad et al., 2015). Moreover, enzymes lipases and esterases, secreted by Rhizopus delemar, R. arrhizus, Achromobacter sp. and Candida cylindracea, have been reported to work on complex polymers like poly (ethylene adipate) and PCL (Jin et al., 2000; Lam et al., 2009). Since degradation of plastics in nature by microorganisms is very slow and extent of degradation is also very less. So, this review is focused on different approaches which enhance microbial degradation of synthetic polymers. As described above, due to their resistance microorganisms cannot decompose intact plastics so, before microbial degradation plastics are pretreated with heat, UV rays, light or different chemicals (Shah et al., 2008; Arkatkar et al., 2010; Wilkes and Aristilde, 2017). Also, blending of non-biodegradable plastics with biodegradable polymers like starch fastens the process of breakdown (Kim, 2003). Moreover, enhanced degradation of plastics by the use of efficient strains obtained from sited where plastic is being dumped for very long periods including both land and marine environments has been studied by various researchers (Singh et al., 2014;Sen and Raut, 2015; Iakovlev et al., 2017). In addition, use of microbial consortium, strain improvement by mutation and biofilm formation by microbes are also covered in this review.

\section{Factors influencing plastic biodegradation}

The process of biodegradation is affected by a number of factors including properties of polymers, conditions in which degradation occurs and characteristics of enzymes involved in degradation. Microbes require water for their growth as well as activity, so moisture rich conditions fastens the process of degradation (Ho et al., 1999). Various microbes require different but specific $\mathrm{pH}$ range for growth. Degradation process of polymers produces some products which change the acidity of medium which in turn change the activity of microbes and further degradation (Auras et al., 2004; Henton et al., 2005). Similarly, temperature also affect the process of degradation as polymers with high melting point are difficult to degrade and enzyme activity also diminishes at higher temperatures (Tokiwa and Calabia, 2004; Tokiwa et al., 2009). Different enzymes 
obtained from bacterial and fungal species are involved in the degradation of various polymers because of presence of different active sites (Kale et al., 2007). Various polymers differs in characteristics properties including molecular weight, shape, size and additives. Polymers with high molecular weight are more resistant to microbial degradation (Tokiwa et al., 2009). Similarly, large surface area of polymers increases the rate of degradation (Stevens, 2003; Kijchavengkul and Auras, 2008). In addition, presence of additives in polymers also affects degradability of polymers significantly (Yang et al., 2005).

\section{Approaches for improving biodegradation of synthetic plastics}

Many bacterial and fungal genera have been identified which possess the capability of degrading different types of plastics (Shimao, 2001). But the rate and extent of degradation process is very low because of high molecular weight and hydrophobicity of polymers (Shah et al., 2008b; Ali et al., 2014). As plastic pollution is increasing day by day in globe, there is dire need to find better ways to combat this problem (Walker et al., 1997; Barnes, 2002; Moore, 2008). Microbial degradation is a cheap and eco-friendly method of plastic degradation (Grover et al., 2015). So, scientists find some ways of enhancing degradation by potential microbes.

\section{Biodegradable polymer blends}

Biodegradation of resistant and inert polymers can be stimulated by addition of additives such as starch, which are biodegradable in nature and serve as nutrient source for microbes and can be easily digested. It was reported that biodegradation ability of Pseudomonas sp. increased by the addition of alternative substrates (Singh and Sharma, 2008). Similarly, P. aeruginosa ATCC13388 showed higher degradation of hydroxypropylated starch blended PE film than nonblended film (Kim, 2003). However, the mechanical strength and durability of plastic get reduced by the addition of such sugar additives (Kim, 2003). Therefore, the nutrient stimulant should not be blended in the polymer structure but added externally.

\section{Promising microorganisms}

Many microorganisms including bacterial and fungal species are involved in the process of biodegradation of different plastics. The degradation abilities of different organisms are different depending upon the type of polymer, growth conditions and enzymes secreted. A number of bacteria and fungi isolated from soil in plastic dumping sites and plastic surfaces have been discovered which effectively degrade synthetic plastics like PE (Veethahavya et al., 2016; Vimala and Mathew, 2016; Ojha et al., 2017), PP, PVC (Iakovlev et al., 2017), PS (Milstein et al., 1992), etc. Various thermophilic microbes are found to be highly potent in degrading different synthetic plastics because of their ability to grow in extreme conditions and secreting many plastic degrading enzymes (Skariyachan et al., 2016; Ganesh et al., 2017). Moreover, many marine microbes possess good biodegradation abilities. As we know, plastic waste is being dumped in oceans from a long period of time. Due to high amount of plastic in water many benthic organisms have developed the abilities to degrade them. This may be because they utilize this waste as new carbon source (Pauli et al., 2017). It was speculated that development of ability of microbes to utilize new carbon sources generated unique features or enzymes in them which are very helpful in dealing with the problem of plastic pollution (Rampelotto, 2014). Among the potential microbial species being employed in the process of biodegradation Pseudomonas, Flavobacterium, Micrococcus, Subtercola, Polaromonas, Leifsonia, Agreia and 
Cryobacterium were isolated from the cryoconite of three glaciers located in northwest Spitsbergen (Singh et al., 2014). Moreover, it was studied that invertebrates possess the capability of degrading different plastics (Bombelli et al., 2017; Brandonet et $a l ., 2018)$. This may be because of microbe present in the gut of the worms in addition to mechanically grinding and shredding of plastics by these organisms. Lastly, microbes can be manipulated genetically by mutation with mutagens such as ultraviolet rays and ethyl methane sulphonate to overproduce the desired enzymes for effective plastic degradation (Muralidhar et al., 2014).

\section{Microbial consortium}

Biodegradation of plastics is a complex and multistep process. It requires breakdown of polymeric compounds into monomeric components and subsequent degradation and assimilation by microbes. It needed a number of enzymes which are highly efficient. All bacteria do not possess all enzymes responsible for effective degradation. So, symbiotic bacterial consortium can degrade resistant plastics more effectively. It was reported that when $P$. aeruginosa MZA85and Bacillus subtilis MZA-75 were used in consortium for PU degradation resulted in the highest weight loss and esterase activity as compared to the individual strains (Shah et al., 2016). One more reason for enhanced biodegradation capabilities in a consortium is microbial interactions with each other. $P$. putida VM15A and Pseudomonas sp. VM15Cwere capable of utilizing PVA as a sole carbon source only when grown together symbiotically but not individually (Shimao, 2001). Similarly, co-culturing of a Flavobacterium sp. with a Pseudomonas sp, resulted in the degradation of PEG due to removal of toxic by-products of PEG degradation produced by Flavobacterium sp. (Gu, 2003).

\section{Pre-treatment of plastics}

As mentioned above, complex synthetic plastics are very difficult to degrade by microbes because of their high molecular weight and inertness. Microbes cannot attack directly on polymeric molecules. So, before microbial degradation polymers needs to be converted into smaller molecules so that microbes can act on them and degrade further (Gilan et al., 2004; Arkatkar et al., 2010; Devi et al., 2016). For this purpose, plastics are treated with different physical and chemical agents prior to biodegradation.

\section{Thermal degradation}

The breakdown of complex molecules into simpler onesby the use of heat is known as thermal degradation however, in the presence of oxygen degradation is known as thermal oxidation. In this process peroxide radicals are produced when products of long chain polymers react with oxygen (Ghosh et al., 2013). Thermal degradation takes place in the presence of visible light while thermal oxidation requires infrared radiations. Many properties of the polymers change due to change in polymeric structure such as optical property, reduction in malleability and molecular weight and many others (Shah et al., 2008).

\section{Photodegradation}

It is the use of high intensity photon particles for the breakdown of long chain polymers into monomeric units. Polymers are able to entrap the solar radiations because of their unique physical and chemical properties. In the presence of oxygen free radicals are created and (Krueger et al., 2015) chain cleavage of polymeric molecules occurs. In this way, smaller molecules are generated which are easily degraded and consumed by different microbial species (Wilkes and Aristilde, 2017). 


\section{Chemical treatment}

A number of chemicals such as nitric acid, sulphuric acid, hydrogen peroxide and hydrochloric acid are used for this purpose. These chemicals create hydroxyl group radicals which in turn oxidize the surface of polymers (Arkatkar et al., 2010; Sen and Raut, 2015). Moreover, it was found that prooxidant additives increase the hydrophobicity of polymeric polyethylene by producing lower molecular weight products and creating carbonyl functional groups (Chiellini et al., 2006; Singh and Sharma, 2008).

\section{Growth medium}

The biodegradation of different plastics is greatly affected by the nature of the growth medium. Microbes need various nutrients for growth and multiplication. Optimum conditions and nutritional requirements of different microbes are different. It was reported by many scientists that some nutrient sources enhance the degradation process while others diminish it. As reported by Hung et al. (2016), if citrate or succinate were added in the medium degradation of PU by $P$. protegens $\mathrm{Pf}-5$ greatly enhanced. A reduction in the cell surface hydrophobicity and attachment of Pseudomonas sp. A to the polymer surface was observed when exposed to carbon- rich and nitrogen-starved conditions (Sanin et al., 2003). This happened due to secretion of extracellular polysaccharides because of overflow of excess carbon (Sanin et al., 2003). So, the increase in concentration of extracellular polysaccharide resulted in improved hydrophobicity of the cell surface (Sanin et al., 2003). Accordingly, cell surface hydrophobicity was increased in Pseudomonas sp. AKS2 on addition of ammonium sulphate to the growth media (Tribedi and Sil, 2013b). The activity of metabolic enzymes is also influenced by trace elements which in turn affect biodegradation of plastics. Moreover, iron and manganese can act as a pro-oxidants of polymers (Singh and Sharma, 2008). However, PVA degradation by Pseudomonas sp. O-3 decreased by the addition of nickel and cobalt in the medium as they serve as inhibitors of enzymes involved in the degradation (Suzuki, 1976). These studies showed the importance of manipulating medium composition for increasing hydrophobicity and attachment of microbial cells to the plastic polymers which in turn enhance biodegradation.

\section{Biofilm formation}

The structure of polymer surface plays very important role in deciding the ability of bacterial cell to attach to the polymer surface (Donlan, 2002). Bacteria tend to attach to hydrophilic surfaces more easily so creation of hydrophilic functional groups on the surface of polymers enhances the attachment of bacteria to plastics. In addition, higher roughness of surfaces not only enhance the attachment but also increases the accessibility of extracellular bacterial enzymes to plastics (Sanin et al., 2003; Tribedi and Sil, 2013c; Nauendorf et al., 2016). The plastic polymers such as PE which has high molecular weight and hydrophobicity require changes in the surface by oxidation reactions or addition of certain chemicals to make it feasible for bacterial colonies to adhere to such polymers (Shah et al., 2008; Sivan, 2011). The bacterial species which possess the ability of biofilm formation on unmodified plastic surfaces have comparatively higher hydrophobicity of their surfaces (Gilan et al., 2004; Tribedi and Sil, 2013b; Devi et al., 2016). As studied by Tribedi et al., (2015), Pseudomonas sp. AKS2 which showed higher potential for degradation of LDPE possesses greater hydrophobicity of their cell surfaces. In addition, it was found that exopolysaccharides 
are secreted by the cells in the biofilm which helps in the attachment (Tribedi and Sil, 2013c). However, it was determined that Pseudomonas sp. AKS2 was not good at degrading other plastics because of differences in their surface structures. Furthermore, biofilm formation is also affected by the nutritional status of the medium (Sivan, 2011). Bacterial cell surface hydrophobicity was found to increase with decreasing glucose and increasing ammonium sulphatecontents (Tribedi and Sil, 2013b). Similarly, there was minimal breakdown of $\mathrm{PE}$ in marine sediments which are rich in organic carbon because of inability of bacterial biofilm formation (Nauendorf et al., 2016). Therefore, biofilm formation directly enhances the process of plastic degradation by bacterial species.

\section{Future prospects}

A limited number of microbes and enzymes are known which can degrade synthetic plastics. Moreover, their degradation capabilities are also very less. Synthetic plastics can be degraded only to some extent. In addition, microbes require pretreatment of these stable plastic polymers with different chemical and physical agents. Therefore, novel microbes are required which are highly potent in degrading synthetic plastics without pretreatment and to a larger extent. Furthermore, currently known microbes can be genetically manipulated by mutation or genetic engineering methods so that the production of plastic degrading enzymes can be increased. Likewise, highly potent enzymes which can degrade most dominant polymers can be identified from noncultivated microorganisms (i.e., global metagenomes). Moreover, structures similar tocellulosome can be developed in microbes which can attack inert and resistant plastics. The biodegradable additives can be added in the plastics which enhance the biodegradability without affecting their useful properties. Lastly, such enzymes which can not only degrade plastic polymers into smaller units but also convert these products into new biopolymers or other beneficial products can be obtained. This may cause significant reduction in the global plastic problem.

\section{References}

Ali, M.I., Ahmed, S., Robson, G., Javed, I., Ali, N., Atiq, N. and Hameed, A. 2014. Isolation and molecular characterization of polyvinyl chloride (PVC) plastic degrading fungal isolates. Journal of Basic Microbiology. 54, 18-27.

Arkatkar, A., Juwarkar, A.A., Bhaduri, S., Uppara, P.V. and Doble, M. 2010. Growth of Pseudomonas and Bacillus biofilms on pretreated polypropylene surface. International Biodeterioration \& Biodegradation.64, 530-536.

Auras, R., Harte, B. and Selke, S. 2004. An overview of polylactides as packaging materials. Macromolecular Bioscience. 4, 835-864.

Barnes, D.K. 2002. Biodiversity: invasions by marine life on plastic debris. Nature. 416, 808-809.

Bombelli, P., Howe, C.J. and Bertocchini, F. 2017. Polyethylene bio-degradation by caterpillars of the wax moth Galleria mellonella. Current Biology. 27, R292R293.

Brandon, A.M., Gao, S.H., Tian, R., Ning, D., Yang, S.S., Zhou, J., Wu, W.M. andCriddle C.S. 2018. Biodegradation of polyethylene and plastic mixtures in mealworms (larvae of Tenebrio molitor) and effects on the gut microbiome. Environmental Science \& Technology. 52, 6526-6533.

Chiellini, E., Corti, A., D’Antone, S. and Baciu, R. 2006. Oxo-biodegradable carbon backbone polymers - oxidative degradation of polyethylene under accelerated test conditions. Polymer Degradation and Stability.91, 2739-2747.

Comăniță, E.D., Hlihor, R.M., Ghinea, C. and Gavrilescu, M. 2016. Occurrence of plastic waste in the environment: ecological and 
health risks. Environmental Engineering and Management Journal.15, 675-685.

Devi, R.S., Kannan, V.R., Natarajan, K., Nivas, D., Kannan, K., Chandru, S. and Antony, A.R. 2016. The role of microbes in plastic degradation. International Journal of Environment and Waste Management. Pp. 341-370.

Donlan, R.M. 2002. Biofilms: microbial life on surfaces. Emerging Infectious Disease. 8, 881-890.

Ganesh, P., Dineshraj, D. and Yoganathan, K. 2017. Production and screening of depolymerising enzymes by potential bacteria and fungi isolated from plastic waste dump yard sites. International Journal of Applied Research.3, 693-695.

Ghosh, S.K., Pal, S. and Ray, S. 2013. Study of microbes having potentiality for biodegradation of plastics. Environmental Science and Pollution Research.20, 43394355.

Gilan, I., Hadar, Y. and Sivan, A. 2004. Colonization, biofilm formation and biodegradation of polyethylene by a strain of Rhodococcus ruber. Applied Microbiology and Biotechnology.65, 97104.

Grover, A., Gupta, A., Chandra, S., Kumari, A. and Khurana, S.P. 2015. Polythene and environment. International Journal of Environmental Science and Technology.5, 1091-1105.

Gu, J.D. 2003. Microbiological deterioration and degradation of synthetic polymeric materials: recent research advances. International Biodeterioration \& Biodegradation. 52, 69-91.

Henton, D.E., Gruber, P., Lunt, J. and Randall, J. 2005. Polylactic acid technology. Natural fibers, Biopolymers, and Biocomposites. 16, 527-577.

Ho, K.L.G., Pometto, A.L. andHinz, P.N. 1999. Effects of temperature and relative humidity on polylactic acid plastic degradation. Journal of Polymers and the Environment.7, 83-92.

Hung, C.S., Zingarelli, S., Nadeau, L.J., Biffinger, J.C., Drake, C.A., Crouch, A.L., Barlow, D.E. and Russell, J.N. 2016. Carbon catabolite repression and impranil polyurethane degradation in Pseudomonas protegens strain Pf-5. Applied and Environmental Microbiology. 82, 60806090.

Iakovlev, V.V., Guelcher, S.A. andBendavid, R. 2017. Degradation of polypropylene in vivo: a analysis of meshes explanted from patients. Journal of Biomedical Materials Research.105, 237-248.

Jin, H.J., Lee, B.Y., Kim, M.N. and Yoon, J.S. 2000. Thermal and mechanical properties of mandelic acid-copolymerized poly (butylene succinate) and poly (ethylene adipate). Journal of Polymer Science Part B: Polymer Physics. 38, 1504-1511.

Kale, G., Kijchavengkul, T.,Auras, R., Rubino, M., Selke, S.E. and Singh, S.P. 2007.Compostability of bioplastic packaging materials: an overview. Macromolecular Bioscience. 7, 255-277.

Kijchavengkul, T. and Auras, R. 2008.Compostability of polymers. Polymer International.57, 793-804.

Kim, M. 2003. Evaluation of degradability of hydroxyl propylated potato starch/polyethylene blend films. Carbohydrate Polymers. 54, 173-181.

Krueger, M.C., Harms, H. and Schlosser, D. 2015. Prospects for microbiological solutions to environmental pollution with plastics. Applied Microbiology and Biotechnology. 99, 8857-8874.

Lam, C.X., Hutmacher, D.W., Schantz, J.T., Woodruff, M.A. and Teoh, S.H. 2009. Evaluation of polycaprolactone scaffold degradation for 6 months in vitro and in vivo. Journal of Biomedical Materials Research Part A. 90, 906-919.

Milstein, O., Gersonde, R., Huttermann, A., Chen, M.J. and Meister, J.J. 1992. Fungal biodegradation of lignopolystyrene graft copolymers. Applied and Environmental Microbiology. 58, 3225-3232.

Mohanty, A., Misra, M. andHinrichsen, G. 2000. Biofibres, biodegradable polymers and biocomposites: an overview. Macromolecular Materials and Engineering.276, 1-24.

Moore, C.J. 2008. Synthetic polymers in the marine environment: a rapidly increasing, long-term threat. Environmental 
Research.108, 131-139.

Muhamad, W.N.A.W., Othman, R., Shaharuddin, R.I. and Irani, M.S. 2015. Microorganism as plastic biodegradation agent towards sustainable environment. Advances in Environmental Biology.9, 8-14.

Muralidhar, S.T., Chethan, C., Kavya, S., Qudsiya, S.S., Shalini, M., Ashik, R. and Aamir, J. 2014. Microbial Degradation of Plastic (LDPE) \& domestic waste by induced mutations in Pseudomanas putida. International Journal of Ethics in Engineering \& Management Education. 1, 2348-4748.

Nauendorf, A., Krause, S., Bigalke, N.K., Gorb, E.V., Gorb, S.N., Haeckel, M., Wahl, M. and Treude, T. 2016. Microbial colonization and degradation of polyethylene and biodegradable plastic bags in temperate fine-grained organic-rich marine sediments. Marine Pollution Bulletin.103, 168- 178.

Ojha, N., Pradhan, N., Singh, S., Barla, A., Shrivastava, A., Khatua, P., Rai, V. and Bose, S. 2017. Evaluation of HDPE and LDPE degradation by fungus, implemented by statistical optimization. Scientific Reports. 7, 39515.

Pauli, N.C., Petermann, J.S., Lott, C. and Weber, M. 2017. Macrofouling communities and the degradation of plastic bags in the sea: an in situ experiment. Royal Society Open Science. 4, 170549.

Rampelotto, P.H. 2014. Polar microbiology: recent advances and future perspectives. Biology 3, 81-84.

Rujnić-Sokele, M. and Pilipović, A. 2017. Challenges and opportunities of biodegradable plastics: a mini review. Waste Management \& Research. 35, 132140.

Saminathan, P., Sripriya, A., Nalini, K., Sivakumar, T. and Thangapandian, V. 2014. Biodegradation of plastics by Pseudomonas putida isolated from garden soil samples. Journal of Advanced Zoology.1, 34-38.

Sanin, S.L., Sanin, F.D. and Bryers, J.D. 2003. Effect of starvation on the adhesive properties of xenobiotic degrading bacteria. Process Biochemistry.38, 909-914.
Sen, S.K. and Raut, S. (2015) Microbial degradation of low density polyethylene (LDPE): a review. Journal of Environmental Chemical Engineering. 3, 462-473.

Shah, A.A., Hasan, F., Hameed, A. and Ahmed, S. 2008b. Biological degradation of plastics: a comprehensive review. Biotechnology Advances.26, 246-265.

Shah, F., Hasan, A., Hameed. and Ahmed, S. 2008. Biological degradation of plastics: A comprehensive review. Journal of Biotechnology. 26, 246-265.

Shah, Z., Gulzar, M., Hasan, F. and Shah, A.A. 2016. Degradation of polyester polyurethane by an indigenously developed consortium of Pseudomonas and Bacillus species isolated from soil. Polymer Degradation and Stability.134, 349-356.

Sharma, M. and Dhingra, H.K. 2016. Poly- $\beta$ hydroxybutyrate: a biodegradable polyester, biosynthesis and biodegradation. British Microbiology Research Journal.14, 1-11.

Sharma, S., Singh, I. andVirdi, J. 2003. A potential Aspergillus species for biodegradation of polymeric materials. Current Science.84, 1399-1402.

Schink, B., Janssen, P.H. and Frings, J. 1992. Microbial degradation of natural and of new synthetic polymers. FEMS Microbiology Reviews.103, 311-316.

Shimao, M. 2001. Biodegradation of plastics. Current Opinion in Biotechnology. 12, 242-247.

Singh, P., Singh, S.M. and Dhakephalkar. 2014. Diversity, cold active enzymes and adaptation strategies of bacteria inhabiting glacier cryoconite holes of High Arctic. Extremophiles. 18, 229-242.

Singh, B. and Sharma, N. 2008. Mechanistic implications of plastic degradation. Polymer Degradation and Stability.93, 561584.

Sivan, A. 2011. New perspectives in plastic biodegradation. Current Opinion in Biotechnology.22, 422-426.

Skariyachan, S., Manjunatha, V., Sultana, S., Jois, C., Bai, V. and Vasist, K.S. 2016. Environmental Science and Pollution Research. 23, 18307.

Stevens, E. 2003. What makes green plastics 
green? Biocycle. 44, 24-27.

Suzuki, T. 1976. Purification and some properties of polyvinyl alcohol-degrading enzyme produced by Pseudomonas O-3. Agricultural and Biological Chemistry.40, 497-504.

Tokiwa, Y. and Calabia, B.P. 2004. Review degradation of microbial polyesters. Biotechnology Letters.26, 1181-1189.

Tokiwa, Y. and Calabia, B.P. 2008. Biological production of functional chemicals from renewable resources. Canadian Journal of Chemistry.86, 548-555.

Tokiwa, Y., Calabia, B.P., Ugwu, C.U. andAiba, S. 2009. Biodegradability of plastics. International Journal of Molecular Sciences.10, 3722-3742.

Tribedi, P. and Sil, A.K. 2013b. Cell surface hydrophobicity: a key component in the degradation of polyethylene succinate by Pseudomonas sp. AKS2. Journal of Applied Microbiology.116, 295-303.

Tribedi, P. and Sil, A.K. 2013c. Low-density polyethylene degradation by Pseudomonas sp. AKS2 biofilm. Environmental Science and Pollution Research.20, 4146-4153.

Tribedi, P., Das Gupta, A. and Sil, A.K. 2015. Adaptation of Pseudomonas sp. AKS2 in biofilm on low-density polyethylene surface: an effective strategy for efficient survival and polymer degradation. Bioresources and Bioprocessing.2, 1-10.

Veethahavya, K.S., Rajath, B.S., Noobia, S. and
Kumar, B.M. 2016. Biodegradation of low density polyethylene in aqueous media. Procedia Environmental Sciences. 35, 709 713.

Vijaya, C. and Reddy, R.M. 2008. Impact of soil composting using municipal solid waste on biodegradation of plastics. Indian Journal of Biotechnology.7, 235-239.

Vimala, P.P. and Mathew, L. 2016. Biodegradation of polyethylene using Bacillus subtilis. Procedia Technology. 24, 232-239.

Walker, T.R., Reid, K., Arnould, J.P. and Croxall, J.P. 1997. Marine debris surveys at Bird Island, South Georgia 1990-1995. Marine Pollution Bulletin. 34, 61-65.

Wilkes, R.A. and Aristilde, L. 2017. Degradation and metabolism of synthetic plastics and associated products by Pseudomonas sp, capabilities and challenges. Journal of Applied Microbiology. 123, 582-593.

Yang, H.S., Wolcott, M., Kim, H.S. and Kim, H.J. 2005. Thermal properties of lignocellulosic filler-thermoplastic polymer biocomposites. Journal of Thermal Analysis and Calorimetry.82, 157-160.

Yoshida, S., Hiraga, K., Takehana, T., Taniguchi, I., Yamaji, H., Maeda, Y., Toyohara, K., Miyamoto, K., Kimura, Y. and Oda, K. 2016. A bacterium that degrades and assimilates poly (ethylene terephthalate). Science. 351, 1196-1199.

\section{How to cite this article:}

Rashmi, Rakesh Kumar and Pathak, D.V. 2020. Approaches for Enhancing Microbial Degradation of Synthetic Plastics: A Review. Int.J.Curr.Microbiol.App.Sci. 9 (01): 910-918. doi: https://doi.org/10.20546/ijcmas.2020.901.101 